\title{
Publication trends of research on uveal melanoma during 2000- 2020: a 20-year bibliometric study
}

\author{
Minyue Xie ${ }^{1,2 \#}$, Qianru Wu ${ }^{3 \#}$, Yefei Wang ${ }^{1,2}$, Shengfang Ge ${ }^{1,2}$, Xianqun Fan ${ }^{1,2}$ \\ ${ }^{1}$ Department of Ophthalmology, Ninth People's Hospital, Shanghai Jiaotong University School of Medicine, Shanghai, China; ${ }^{2}$ Shanghai Key \\ Laboratory of Orbital Diseases and Ocular Oncology, Shanghai, China; ${ }^{3}$ Department of Ophthalmology, Peking University Third Hospital, Beijing \\ Key Laboratory of Restoration of Damaged Ocular Nerve, Peking University Third Hospital, Beijing, China \\ Contributions: (I) Conception and design: X Fan, M Xie, Q Wu; (II) Administrative support: X Fan; (III) Provision of study materials or patients: \\ None; (IV) Collection and assembly of data: M Xie, Q Wu, Y Wang, S Ge; (V) Data analysis and interpretation: M Xie; (VI) Manuscript writing: All \\ authors; (VII) Final approval of manuscript: All authors. \\ \#These authors contributed equally to this work. \\ Correspondence to: Xianqun Fan. Department of Ophthalmology, Ninth People's Hospital, Shanghai Key Laboratory of Orbital Diseases and Ocular \\ Oncology, Shanghai Jiao Tong University School of Medicine (SJTU-SM), Shanghai 200025, China. Email: fanxq@sjtu.edu.cn.
}

\begin{abstract}
Uveal melanoma (UM) is the most prevalent primary intraocular malignancy in adults. Despite a high rate of success in controlling it as a local disease, it is prone to distant metastasis, and its mechanism of metastasis has not been elucidated. This study analyzes trends in UM research and compares contributions from different countries, regions, institutions and authors. We collected all publications related to UM published from 2000 to 2020 from the Web of Science database. GraphPad Prism 6 was used to collect publication data and analyze publication trends. VOSviewer was used for data visualization. A total of 1,710 publications were considered. The United States contributed the most publications [668] and citations (19,605 times) as of 2020 with the highest H-index value [67]. Keywords were classified into three clusters, namely, clinical study, tumor-related study and gene mutation-related study. Average appearing years (AAY) of keywords were calculated. BAP1 (AAY of 2016.3), SF3B1 (AAY of 2015.8) and GNA11 (AAY of 2015.5) were identified as major focuses of this field. We conclude that the United States, Germany, England and the Netherlands have been the most productive regions in terms of UM research over the past two decades. Gene mutations such as GNAQ, GNA11 and BAP1 mutations are identified as potential research focuses.
\end{abstract}

Keywords: Bibliometric analysis; publication; uveal melanoma (UM); mutations; metastasis

Submitted May 04, 2020. Accepted for publication Sep 18, 2020.

doi: $10.21037 /$ atm-20-3700

View this article at: http://dx.doi.org/10.21037/atm-20-3700

\section{Introduction}

Among ocular tumors, uveal melanoma (UM), which is the most prevalent primary intraocular malignancy in adults arising within the uveal tract, iris, or ciliary body (1). It is a rare form of melanoma that accounts for approximately $3 \%$ to $5 \%$ of all melanoma cases (2). In the United States and Europe, the incidence of UM is five to six per million people, while in Australia, the incidence is seven cases per million people (3). However, the ten-year mortality rate of UM in the United States is $50 \%$, which is markedly higher than those of other melanoma subtypes (4). With the introduction of novel treatment modalities, more patients have been treated with eye-sparing treatments, such as radiation or transpupillary thermotherapy, though the five-year survival rate has remained almost unchanged (4). Studies have shown that intrinsic risk factors for UM include Caucasian race (5); fair hair, skin complexion and iris coloring; UM family history; previous cutaneous malignant melanoma history and specific genetic abnormalities (1). Extrinsic risk factors include artificial UV or blue light exposure and a history of occupational exposure to chemicals (6). 


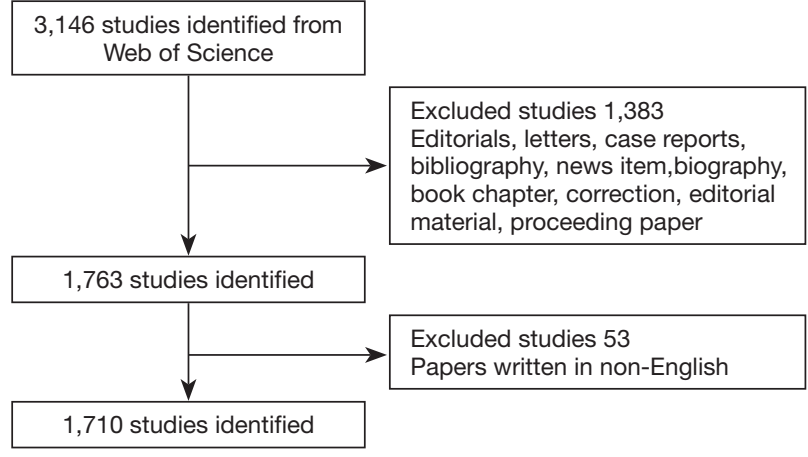

Figure 1 Flow diagram of UM researches inclusion process. The detailed process of retrieving and screening. UM, uveal melanoma.

Despite a high rate of success in controlling local disease through surgery or radiotherapy, nearly $50 \%$ of patients with UM will metastasize within 15 years of the initial diagnosis. The most common initial site of metastasis is the liver $(89 \%)$, followed by the lungs $(29 \%)$ and bones (17\%) (7-9). However, most patients with metastasized UM survive less than 12 months. This poor prognosis is mainly attributed to the fact that systemic chemotherapy is not highly effective in treating metastatic UM $(10,11)$. In addition to chemotherapy, potential treatments for metastatic UM include immunotherapy and targeted therapy (11). Due to the particular important effects of the immune system on cancer cells, immunotherapy and targeted therapy have drawn extensive attention. However, despite impressive effects of immune-based therapies on metastatic cutaneous melanoma, such therapies appear unsatisfactory in treating UM to date (12).

Bibliometrics is an optimal means to evaluate specific trends in the research regarding a certain field over time (13). Bibliometric methods are employed to quantitatively and qualitatively analyze publications, including books and journal articles. Meanwhile, such an analysis can characterize and predict the development of a certain field and can be used to compare contributions across countries, institutions and journals. Specifically, a bibliometric analysis has proven important for the formulation of policies and clinical guidelines, making it attractive as an analytical method.

This work presents a comprehensive analysis of the current state of global UM research based on Web of Science (WOS) data. We identify trends in UM research and predict potential focuses within this field via bibliometrics $(14,15)$.

\section{Methods}

\section{Data sources and search methods}

The Science Citation Index-Expanded (SCI-E) of the WOS has been recognized as the most suitable database for bibliometric analysis. Accordingly, we conducted a literature search for the years 2000 to 2020 using the WOS database.

All searches were completed on January 17, 2020 to avoid biases introduced by the daily renewal of the open database. The following search terms were used: TI = (uveal melanoma) AND Language = English. Finally, we included all the original articles and reviews in the core database to obtain a total of 1,710 publications meeting the search criteria. Our inclusion and exclusion methods are illustrated in Figure 1.

\section{Data collection}

All data (i.e., titles, publication dates, countries and regions, authors, sums of citations and $\mathrm{H}$-indexes) were extracted from the included publications. Microsoft Excel 2010 (Redmond, Washington, USA), GraphPad Prism 6 (GraphPad Prism Software Inc., San Diego, CA) and VOSviewer (Leiden University, Leiden, the Netherlands) were used to input and analyze the data.

\section{Bibliometric analysis}

The characteristics of all publications considered were examined through the Web of Science. Relative research interest (RRI) was measured as the number of publications in a certain field divided by all publications of all fields. The $\mathrm{H}$-index, denoting that a scholar or region has published $\mathrm{H}$ papers that have each been cited at least $\mathrm{H}$ times, has been widely accepted to reflect the productivity and citation impact of a scholar or region (16).

The prediction model $f(x)=a x 3+b x 2+c x+d$ was generated by Microsoft Excel 2010 according to the cumulative publications to analyze time trends and future publication patterns. In this formula, $\mathrm{x}$ is time (year) and $\mathrm{f}(\mathrm{x})$ denotes the cumulative number of publications produced as of a given year. GraphPad Prism 6 was applied to analyze the quantity and quality of studies published in various regions. VOSviewer, an application used to analyze correlations between highly cited literature and productive authors, was used to construct a co-occurrence network of keywords from titles and abstracts. Moreover, keywords were classified into disparate clusters and simultaneously 

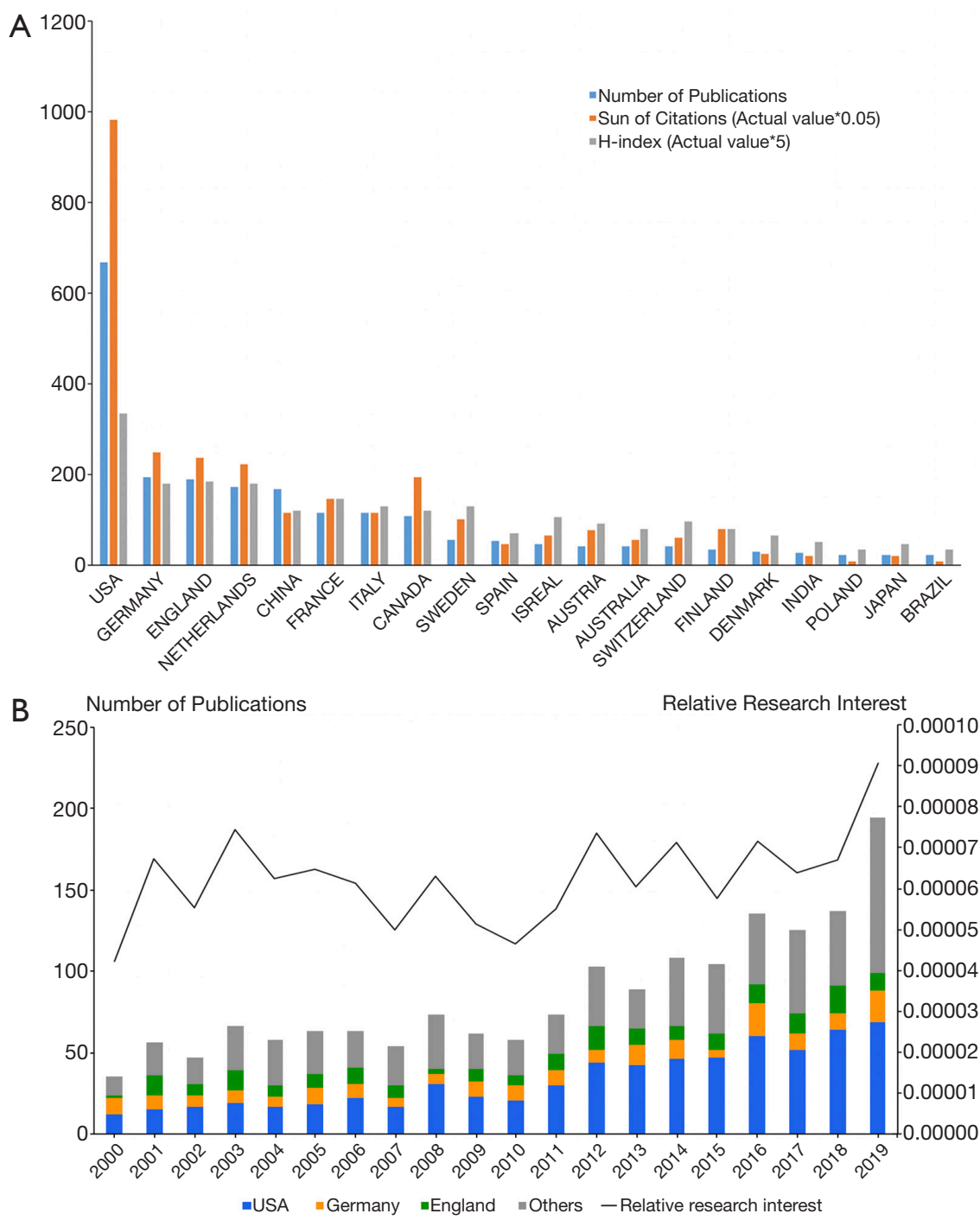

Figure 2 Contributions to the UM research of different countries/regions. (A) The number of publications, citations ( $\times 0.05)$, and $\mathrm{H}$-index value $(\times 5)$ of the top 20 countries or regions; (B) histogram shows the amount of publications worldwide and the top 3 countries. Line chart shows the time course of RRI. UM, uveal melanoma; RRI, relative research interest.

color-coded by time course. The average appearing year (AAY) was used to evaluate the novelty of a research topic.

\section{Results}

\section{Countries' contributions to global publications}

From 2000 to 2020, the United States produced the most publications $(668,39.1 \%)$, followed by Germany (194, $11.4 \%$ ) and England (188, 11.0\%) (Figure 2A). Furthermore, for each year over the past two decades, the United States published the most papers (Figure 2B). With respect to the number of publications per year, the most studies were published in 2019 (194, 11.3\%). A comparison to the number of works published in the whole field based on the RRI value shows that global attention to this field was approximately $0.006 \%$ before 2018 and increased to $0.009 \%$ in 2019. While it was not until 2006 that China published its first paper in this field, over the past decade, the number of Chinese publications has risen at a surprising rate, and it eventually rose to a rank of fifth.

After excluding countries and regions that are not connected to other countries, 28 countries and regions 

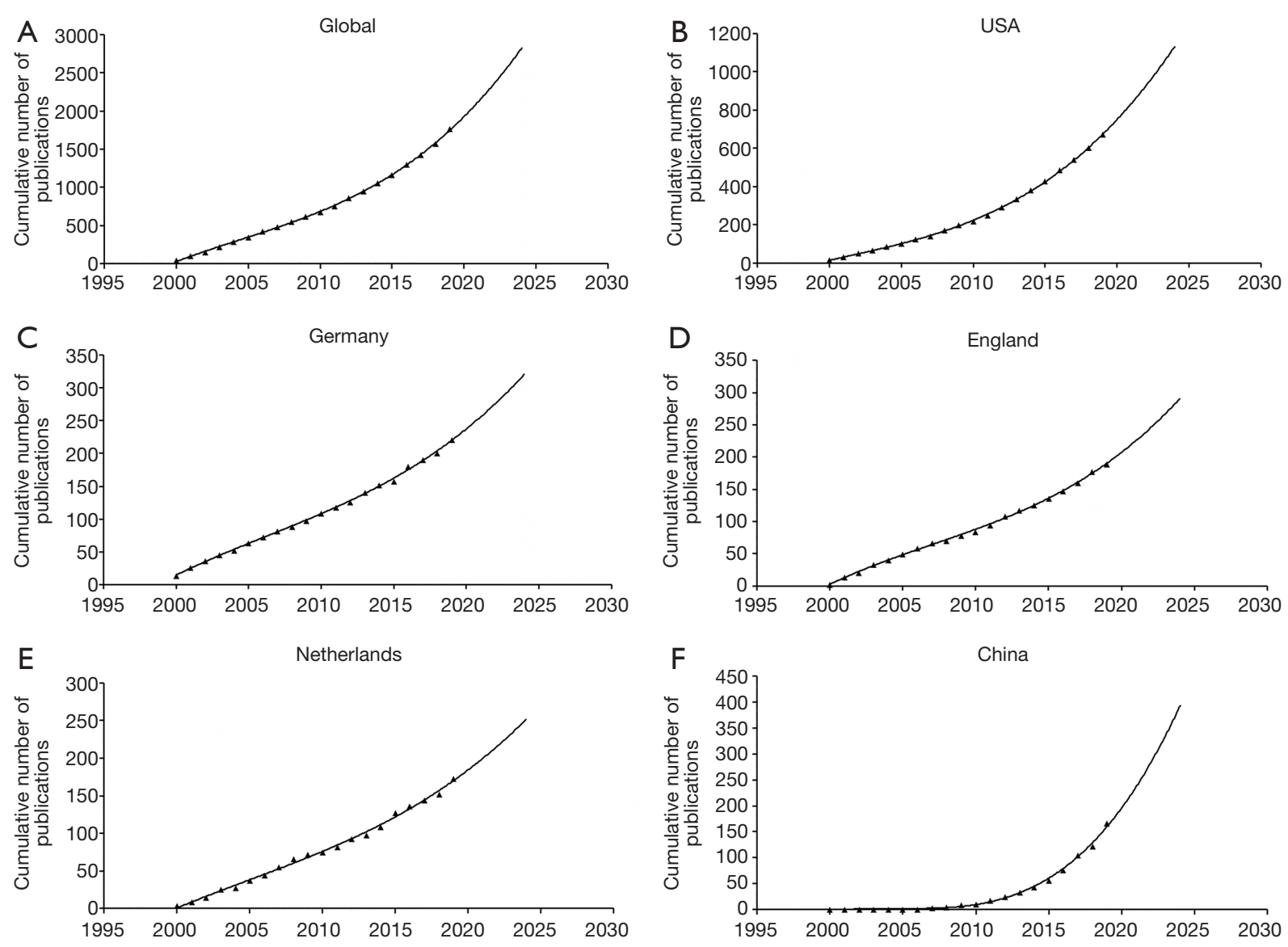

Figure 3 Fitting curves of publications growth trends. (A) Global; (B) the United States; (C) Germany; (D) England; (E) Netherlands; (F) China.

are analyzed using VOSviewer (Figure S1). The cooccurrence relations of countries and regions resulted in five clusters: (I) the United States, China, Japan, India, Turkey; (II) England, Germany, Italy, France, Switzerland, Spain, Finland, Austria, Belgium, Poland, Portugal; (III) the Netherlands, Australia, Scotland, Israel, Ireland; (IV) Sweden, Denmark, South Korea, Norway, Hungary; and (V) Canada, Brazil.

\section{Citations and $\mathrm{H}$-index}

From a citation report retrieved from the WOS database, all publications related to UM have been cited 38,353 times since 2000 (21,178 citations without self-citations) with each paper being cited 22.4 times, on average. Papers from the United States were cited significantly more frequently cited than those from other countries, thus accounting for $51.1 \%$ of the total citations $(19,605$ citations and
15,374 citations without self-citations). The United States also achieved the highest paper H-index [67], while Germany ranked second in total citations at 4,982 citations (4,546 citations without self-citations), and England ranked third with 4,729 citations (4,261 citations without selfcitations). Germany's H-index [36], however, was found to be slightly lower than England's [37] (Figure S2A).

\section{Publication growth trend predictions}

The growth in UM publication predicted from model fitting curves demonstrates that the cumulative number of publications was significantly related to time (Figure 3), and publication trends for the following five years were estimated based on the cumulative number of works published over the past two decades. It is apparent that the volume of global publications has steadily and slowly increased, echoing trends in several major countries such as 


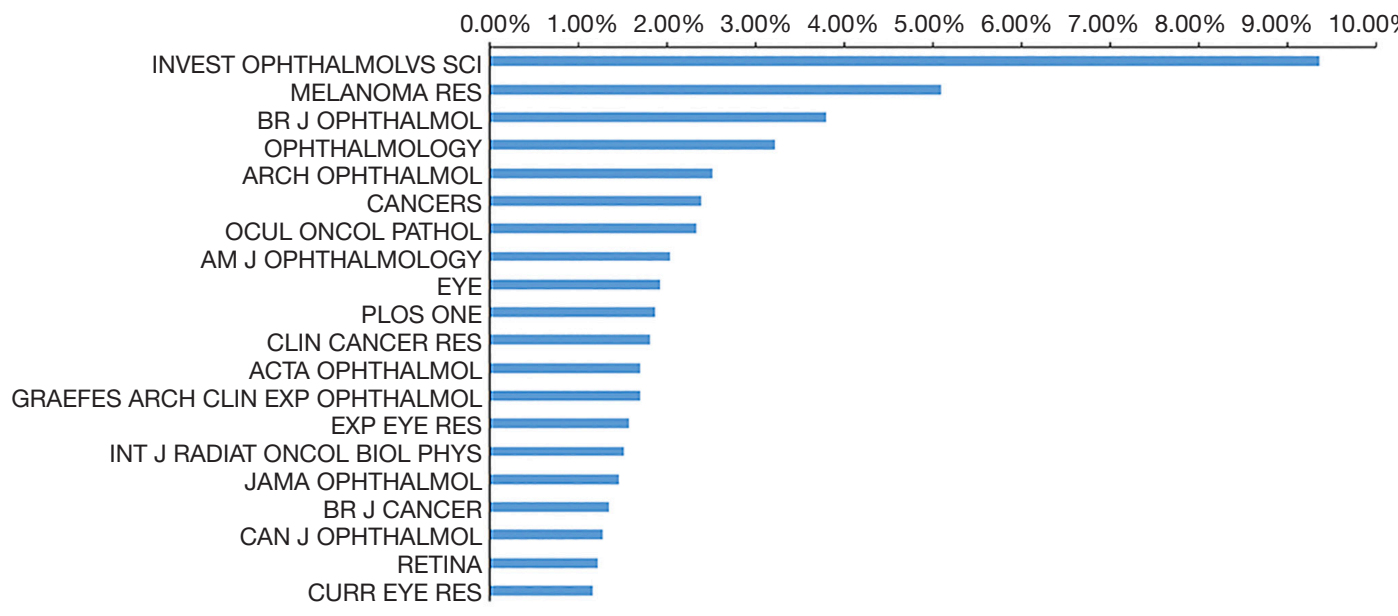

B

$0.00 \% 1.00 \% 2.00 \% 3.00 \% 4.00 \% 5.00 \% 6.00 \% 7.00 \% 8.00 \%$

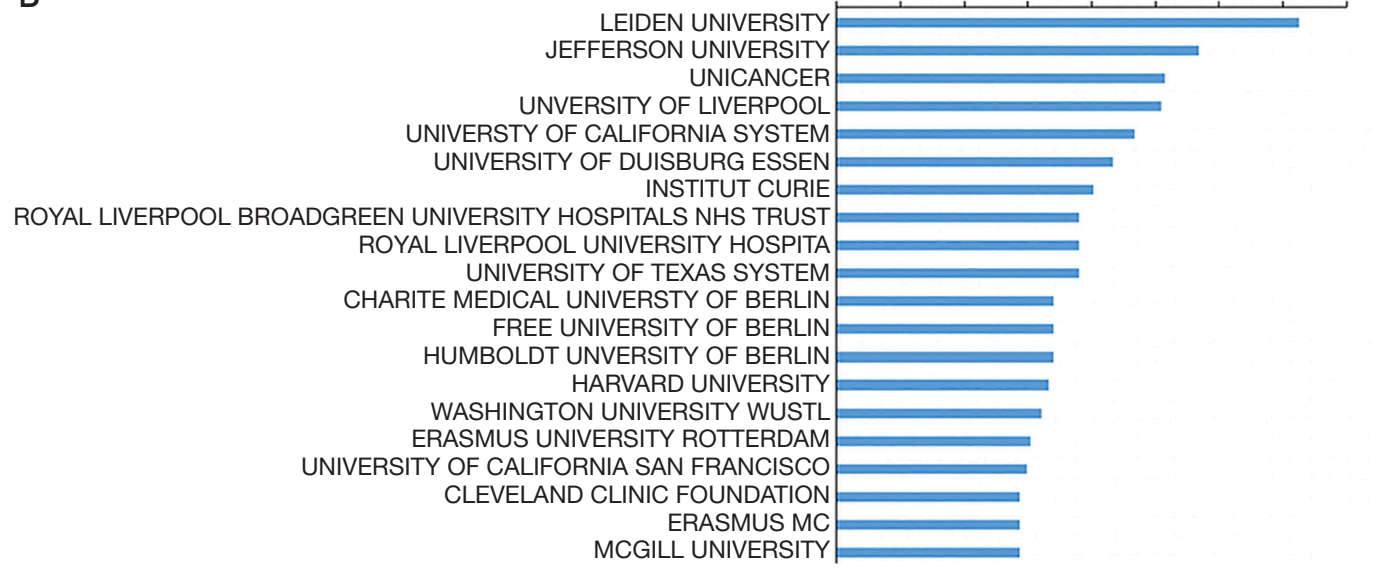

Figure 4 Distribution of journals and institutions focusing on UM. (A) Top 20 journals with the most publication in this field; (B) top 20 institutions with the most publication in this field. UM, uveal melanoma.

the United States and Germany (Figures 3B,C), while China has exhibited significantly faster growth despite its late start in research with respect to this field (Figure 3F).

\section{fournals publishing research on UM}

Nearly half of the publications were published in the 20 journals listed in Figure 4 (844, 46.7\%), with Investigative Ophthalmology and Visual Science publishing the most works, specifically, 160 publications. Melanoma research ranks second with 87 publications, while British fournal of Ophthalmology, which has published 65 papers in this field, ranks third and ophthalmology ranks fourth with 43 works published over the past 20 years. Other high impact journals, such as Nature, published high-quality research in 2009, and Science and the New England Fournal of Medicine published one article each in 2010.

\section{Institutions publishing research on UM}

With respect to institutions, Leiden University in the Netherlands published the most studies (124, 7.3\%) followed by Jefferson University in the United States (97, 5.7\%). Of the top 20 institutions identified for their UM research, seven are in the United States, four are German institutions, three are in England, three are in the Netherlands, two are in France and one is in Canada.

\section{Authors publishing research on UM}

The top ten authors have published a total of 558 publications, thus accounting for $32.6 \%$ of all work in this field, but Jager MJ of Leiden University, publishing 97 papers on UM, ranks first in the number of publications (Table 1). Harbour JW of Washington University (WUSTL) 
Table 1 Top 10 authors with the most publications in UM research

\begin{tabular}{lcccc}
\hline Author & Country & Affiliation & No. of publications & No. of citations \\
\hline Jager MJ & Netherlands & Leiden University & 97 & 2,467 \\
Harbour JW & USA & Washington University (WUSTL) & 67 & 4,006 \\
Shields CL & USA & Jefferson University & 52 & 1,095 \\
Shields JA & USA & Jefferson University & 51 & 1,869 \\
Luyten GPM & Netherlands & Leiden University & 48 & 1,606 \\
Singh AD & USA & Cleveland Clinic Foundation & 48 & 606 \\
Burnier MN & Canada & Mcgill University & 46 & 1,278 \\
Coupland SE & England & University of Liverpool & 42 & 1,245 \\
Damato B & England & University of Liverpool & 36 & 994 \\
De Klen A & Netherlands & Erasmus University Rotterdam & 36 \\
Bornfeld N & Germany & University of Duisburg Essen & & 1,274 \\
\hline
\end{tabular}

UM, uveal melanoma.

ranks second, albeit he has the most citations (4,006 times). Following Jager and Harbour is Shield CL of Jefferson University, who has published 65 papers and has been cited 2,095 times. Among the top ten authors, four are from the United States, three are from the Netherlands, two are from England and the remaining two are from Germany and Canada, respectively. Notably, Bastian BC of the University of California, San Francisco and the UCSF Helen Diller Family Comprehensive Cancer Center ranks fourth in the number of citations (1,994 times) even though he is not in the top 50 in terms of total publications with only 12 papers.

Given that the effective and close cooperation between clinical researchers can improve the quality of observational research and randomized trials, the collaboration network from 2000 to 2020 is presented in Figure S2. The size of the node is proportional to the total strength of the link of each researcher as evidenced by Jager MJ, who has engaged in the greatest number of collaborations with other researchers and has maintained close cooperation with many researchers in recent years. Harbour JW and Shield CL also cooperate with a large number of researchers, but the majority of the cooperation occurred prior to 2012 .

\section{Analysis of keywords and focuses of UM research}

We analyzed the keywords found over 20 times in the titles and abstracts of all 1,710 publications using VOSviewer. After merging words of the same meaning and excluding meaningless words, 89 terms were identified and classified into tumor-related study, clinical study and gene mutationrelated study clusters (Figure 5A). With respect to the clinical study cluster, the keywords diameter (159 times), tumor thickness (139 times), plaque brachytherapy (138 times) and chemotherapy (73 times) are among the most frequently mentioned. Regarding the tumor-related study cluster, the primary keywords include cell (572 times), apoptosis (103 times), receptor (101 times) and miRNA (82 times). In the gene mutation-related study cluster, the keywords include BAP1 (170 times), GNAQ (126 times), GNA11 (103 times) and SF3B1 (48 times).

We then color-coded all keywords based on the AAY of each word (Figure $5 B$ ). Keywords shown in yellow such as BAP1 (cluster 3, AAY of 2016.3), SF3B1 (cluster 3, AAY of 2015.8), GNA11 (cluster 3, AAY of 2015.5), and miRNA (cluster 2, AAY of 2015.4) appear most recently, and hence, the gene mutation-related study cluster may constitute a new research trend.

\section{Discussion}

\section{UM research trends}

Our observations indicate that the United States, Germany and England ranked highest in terms of total number of citations and $\mathrm{H}$-index values in the area of UM research. There is no doubt that the United States has made the greatest contributions. While UM was first described by 

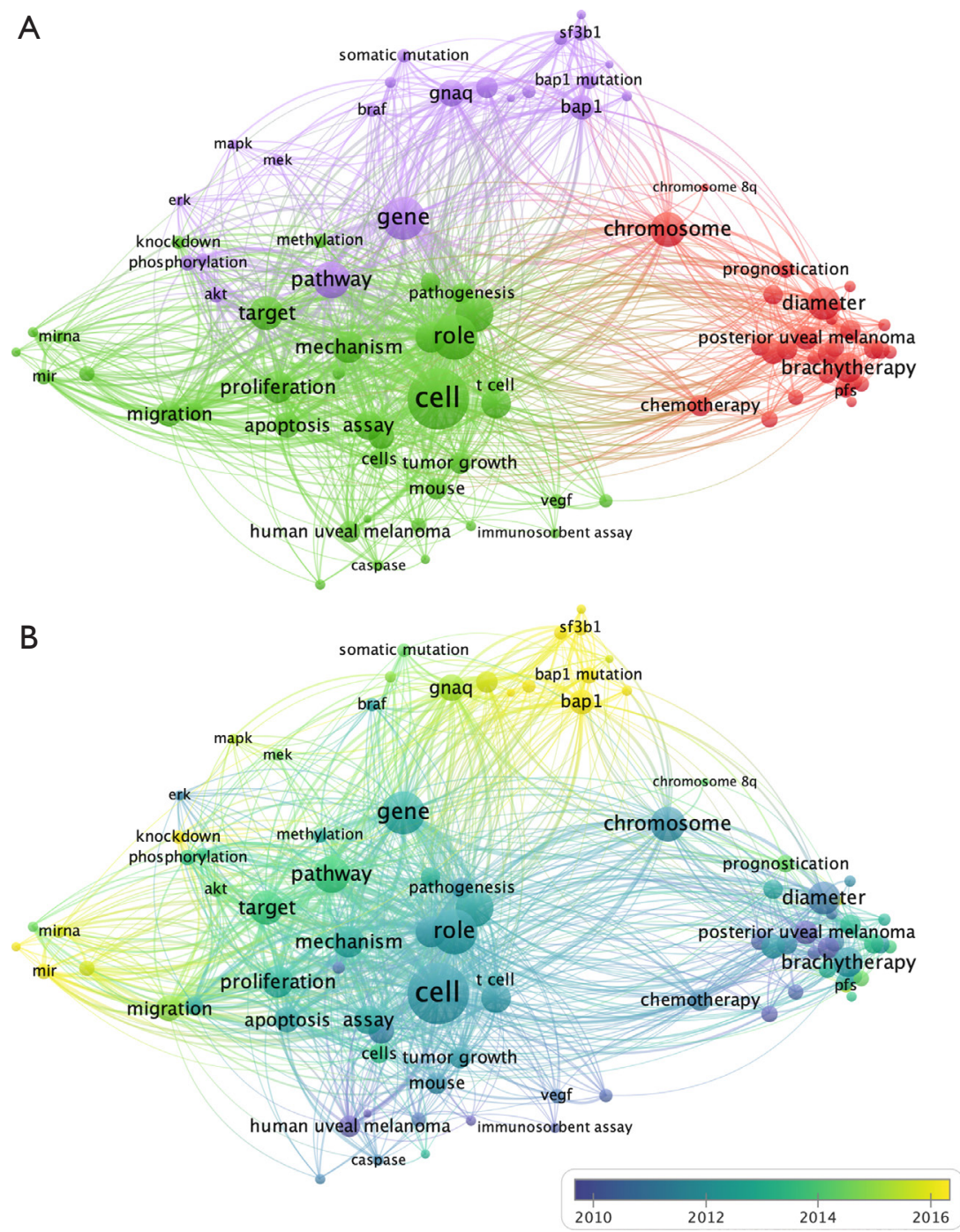

Figure 5 The analysis of keywords in UM researches. (A) Mapping of the keywords in UM researches. All keywords were divided into three clusters and given different colors: tumor related research (left in green), clinical research (right in red), and gene mutation related research (up in purple). The circle with a large sizer represented a higher frequency of the keywords; (B) distribution of keywords based on the average time of appearance. Yellow indicates recent appearance, and blue indicates early appearance. Lines represent two keywords appearing in the same publication, thicker lines indicate closer relationships. UM, uveal melanoma.

two Scottish surgeons in the 1800s (17), American scholars focused on this disease earlier than other scholars from other countries. In addition, due to a higher incidence of $\mathrm{UM}$ in high latitude areas, the incidence of UM in the United States is 5.1 cases per million people per year (18), while in Asian countries, such as South Korea, the incidence of UM reaches only 0.6 cases per million per year (19). European countries such as the Netherlands, Germany, and Switzerland, which also have higher incidence rates of 4 to 5 cases per million, have also made strong contributions (20).
Furthermore, basic medical research conditions appear to be superior and clinical trials seem to be more professional and standardized in the United States.

While China ranks fifth in the total number of publications, its citation and $\mathrm{H}$-index values are ranked eighth. Although China has contributed a large number of publications, the quality of such research must be improved. This may be attributed to the uneven clinical and scientific research competencies of Chinese hospitals. In addition, the inconsistencies and incomplete electronification of 
Table 2 Top 10 publications with the most citations in UM research

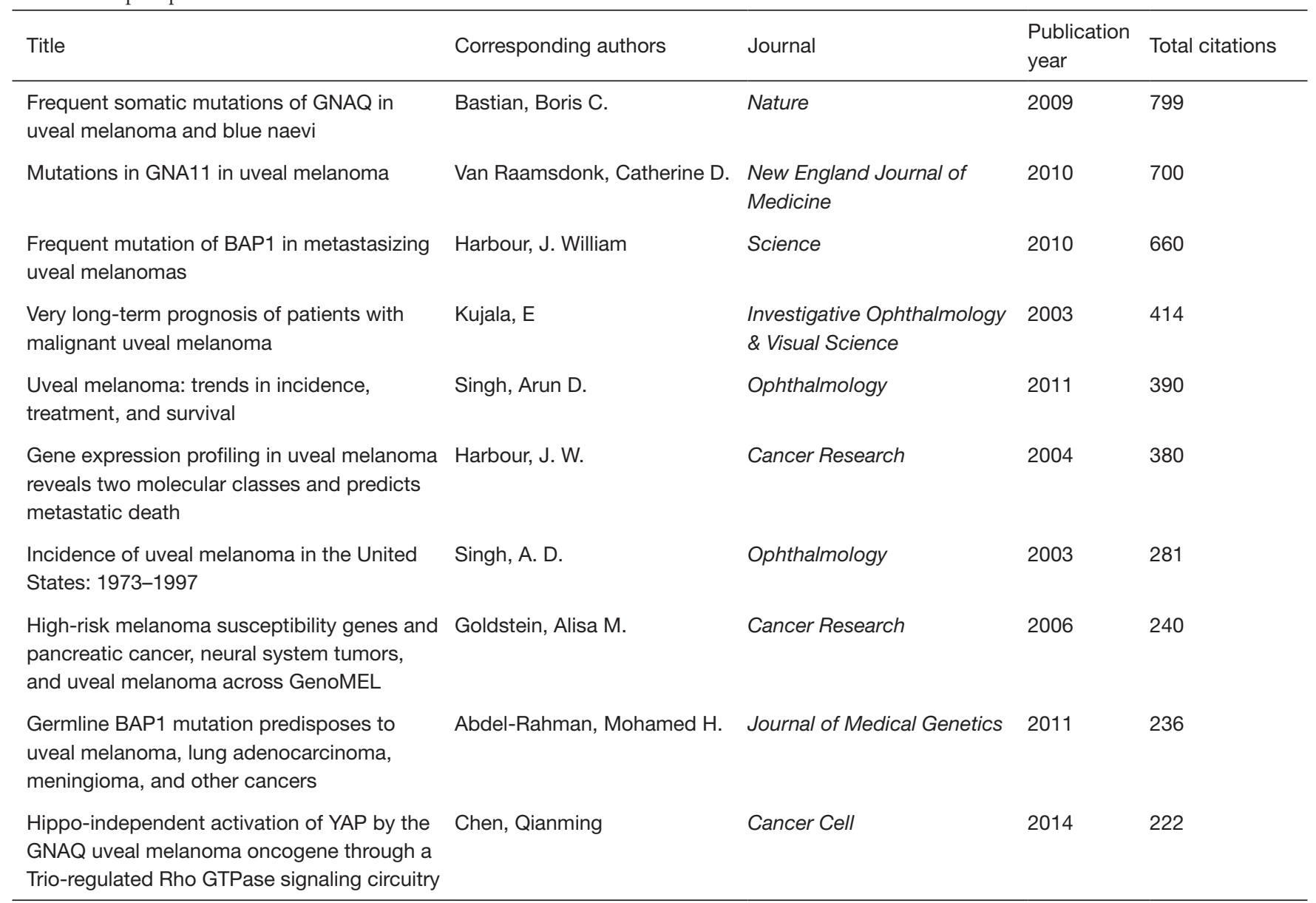

UM, uveal melanoma.

China's medical records system have created obstacles to the execution of multicenter randomized clinical trials (RCTs).

As depicted by our model fitted time curve, global research on UM has increased steadily over time. Notably, China's research in this field started late but developed rapidly as China has gradually ascribed importance to research on diseases over the past decade. Due to China's large population, Chinese researchers can examine a relatively large number of cases, which is advantageous for the study of rare diseases such as UM.

Notably, journals of ophthalmology such as Investigative Ophthalmology and Visual Science, the British Journal of Ophthalmology and Ophthalmology were the primary journals publishing research on UM. Thus, future developments in this field are more likely to be published in these journals.

Jager MJ of Leiden University, Harbour JW of
Washington University (WUSTL), and Shields CL and Shields JA of Jefferson University have published the most research in this field. Jager MJ has mainly focused on the investigation of molecular targets for the prediction and treatment of metastatic UM, while Harbour JW has focused on pathogenic gene mutations. These scholars have been pioneers in the research of UM, and their studies will continue to guide future research and clinical treatment in this field.

\section{UM research focuses}

Published papers with high academic impact tend to be cited frequently. The ten most cited publications on UM research are listed in Table 2. In recent years, with the discovery of GNAQ, GNA11 and BAP1 mutations, the molecular mechanism of metastasis UM has gradually been 
revealed with research having identified these metastasisrelated mutations using exome sequencing (21-23). A paper entitled "Frequent somatic mutations of GNAQ in uveal melanoma and blue naevi" published in Nature in 2009 has been cited 799 times. In 2010, mutations of GNA11 in UM were first reported in the New England Journal of Medicine. In the same year, the mutation of BAP1 in metastasizing UM was also reported for the first time in Science. Immediately afterwards, pathways affected by these three mutations and potential treatments were examined $(24,25)$. There has also been a focus on GNAQ/GNA11 mutations, which constitutively activate Gaq G proteins and initiate oncogenic events in UM. A study published in Cancer Cell in 2014 reveals that the mutation of GNAQ and GNA11 could stimulate YAP via Trio-Rho/Rac signaling circuitry, thereby identifying YAP as a potential therapeutic target of UM metastasis (26). An article published in Cancer Cell in 2017 also finds that the small GTPase ARF6 mediates oncogenic Gaq signaling, subsequently inducing downstream $\beta$-catenin signaling pathways (27). In the same year, it was proved that GNAQ signaling mediates MAPK activation via PKC phosphorylation and RasGRP3 activation, thus potentially creating opportunities for refined therapeutic targeting in UM (28). In 2019, another study published in Cancer Cell demonstrated that focal adhesion kinase (FAK) encoded by PTK2 mediates the phosphorylation of MOB1, which subsequently leads to YAP-dependent tumorigenesis (29). The mutation of CYSLTR2, which exhibits high activation through Gaq, was also defined, thus providing a potential therapeutic strategy for UM (30). Two additional studies that sequenced the exons of primary UM relative to blood samples identified EIF1AX and SF3B1 mutations $(31,32)$. Unlike GNAQ/GNA11, which are considered early events in the development of UM, mutations of BAP1, EIF1AX and SF3B1 were found to be strongly associated with the late development of metastases in most cases (33). A retrospective cohort study published in $7 A M A$ Ophthalmology in 2015 concluded that germline BAP1 mutations are associated with larger tumors and ciliary body involvement (34). Later, BAP1 was found to regulate cell cycle via E2F1 target genes in UM cells (35). Another retrospective case series published in Ophthalmology in 2018 also proved that BAP1 immunoreactivity is significantly lower in primary UM patients treated by enucleation, suggesting that nuclear BAP 1 stain is a significant independent predictor of tumor metastasis (36). In targeting BAP1 mutations, researchers have found that histone deacetylase (HDAC) inhibitors can arrest UM cell growth and may have therapeutic potential (37).

In recent years, miRNA has become another research focus in this field. A latent key effector of p53, microRNA$34 \mathrm{a}$ (miR-34a), has been found to be a potential tumor suppressor in UM. The introduction of miR-34a affects the expression of c-Met and subsequently affects the cell cycle (38). Another work concluded that miR-137 acts as a tumor suppressor of UM cell proliferation by downregulating the oncogenic transcription factor MITF and the cell cycle-related protein CDK6 (39). Another p53-dependent miRNA, miR-182, was found to act as a potent tumor suppressor by decreasing expression levels of MITF, BCL2 and cyclin D2 (40). The miR-181 family was also found to be a key negative regulator of cell cycle progression (41). Researchers have thus inserted miRNA response elements (MREs) of miR-34a, miR-137 and miR182 into the tumor necrosis factor (TNF)-related apoptosisinducing ligand (TRAIL) coding sequence to generate an MRE-regulated TRAIL expression system via an adenoviral vector. This novel strategy-regulated gene therapy vector has proved to be a promising biological agent for the treatment of UM $(42,43)$.

While the pathogenesis of cutaneous melanoma is similar to that of UM, UM exhibits different clinical and biological behaviors. Studies have shown that mutations of PTEN and BRAF, which are relatively common in cutaneous melanoma, are not found in UM $(44,45)$. However, mitogen-activated protein kinase/extracellular signalregulated kinase was found to be constitutively activated in $\mathrm{UM}$, indicating that the activation of the MAPK pathway is related to the development of UM (46). Clinical studies published in 2016 indicate that PD-1 and PD-L1 inhibitors, which demonstrate effects in the treatment of advanced cutaneous melanoma, confer durable objective tumor responses in relatively few patients with metastatic UM (47). A study published in Nature Communication in 2018 claimed that patients with MBD4 germline deleterious mutations exhibit high sensitivity to PD-1 inhibitors, a result that was proven to be related to hypermutated $\mathrm{CpG}>\mathrm{TpG}$ burden (48). The adoptive transfer of tumor-infiltrating lymphocytes (TIL) has been identified as another efficient treatment of metastatic melanoma (49). An article published in Lancet Oncology in 2017 reported a single center phase 2 study found that the transfer of TIL could mediate tumor regression in patients with metastatic UM (50). Future studies should focus on ways to maintain clinical responses completely and durably. 


\section{Strengths and limitations}

We accessed publications on UM extracted from the WOS database and analyzed the data comprehensively and objectively. Despite this, some restrictions were unavoidable as we only considered publications written in English, and thus, we may have overlooked important research published in other languages. Moreover, the more recent papers could not accumulate a large number of citations at the time of this study, which may have affected our conclusions to some degree.

\section{Conclusions}

The present study illustrates global trends in UM research. The United States has contributed the most research and holds the leading position in this field. The latest progress can be found in Investigative Ophthalmology and Visual Science, the British Fournal of Ophthalmology and Ophthalmology. Jager MJ and Harbour JW may be good candidates for academic collaboration in this field. Gene mutation and pathogenesis pathway-related research has not yet been thoroughly studied and is gradually becoming a focus of research in this field.

\section{Acknowledgments}

Funding: This work was supported by grants from the National Natural Science Foundation of China (Grants U1932135, 81772875), National Key Research and Development Plan (2018YFC1106100), The Science and Technology Commission of Shanghai (17DZ2260100, 19JC1410200).

\section{Footnote}

Peer Review File: Available at http://dx.doi.org/10.21037/ atm-20-3700

Conflicts of Interest: All authors have completed the ICMJE uniform disclosure form (available at http://dx.doi. org/10.21037/atm-20-3700). The authors have no conflicts of interest to declare.

Ethical Statement: The authors are accountable for all aspects of the work in ensuring that questions related to the accuracy or integrity of any part of the work are appropriately investigated and resolved.

Open Access Statement: This is an Open Access article distributed in accordance with the Creative Commons Attribution-NonCommercial-NoDerivs 4.0 International License (CC BY-NC-ND 4.0), which permits the noncommercial replication and distribution of the article with the strict proviso that no changes or edits are made and the original work is properly cited (including links to both the formal publication through the relevant DOI and the license). See: https://creativecommons.org/licenses/by-nc-nd/4.0/.

\section{References}

1. Ghazawi FM, Darwich R, Le M, et al. Uveal melanoma incidence trends in Canada: a national comprehensive population-based study. Br J Ophthalmol 2019;103:1872-6.

2. Komatsubara KM, Carvajal RD. Immunotherapy for the Treatment of Uveal Melanoma: Current Status and Emerging Therapies. Curr Oncol Rep 2017;19:45.

3. Kaštelan S, Antunica AG, Oresković LB, et al. Immunotherapy for uveal melanoma - Current knowledge and perspectives. Curr Med Chem 2020;27:1350-66.

4. Singh AD, Turell ME, Topham AK. Uveal melanoma: trends in incidence, treatment, and survival. Ophthalmology 2011;118:1881-5.

5. Rishi P, Koundanya VV, Shields CL. Using risk factors for detection and prognostication of uveal melanoma. Indian J Ophthalmol 2015;63:110-6.

6. Di Cesare S, Maloney S, Fernandes BF, et al. The effect of blue light exposure in an ocular melanoma animal model. J Exp Clin Cancer Res 2009;28:48.

7. Yonekawa Y, Kim IK. Epidemiology and management of uveal melanoma. Hematol Oncol Clin North Am 2012;26:1169-84.

8. Buder K, Gesierich A, Gelbrich G, et al. Systemic treatment of metastatic uveal melanoma: review of literature and future perspectives. Cancer Med 2013;2:674-86.

9. Oliva M, Rullan AJ, Piulats JM. Uveal melanoma as a target for immune-therapy. Ann Transl Med 2016;4:172.

10. Kuk D, Shoushtari AN, Barker CA, et al. Prognosis of Mucosal, Uveal, Acral, Nonacral Cutaneous, and Unknown Primary Melanoma From the Time of First Metastasis. Oncologist 2016;21:848-54.

11. Dogrusöz M, Jager MJ, Damato B. Uveal Melanoma Treatment and Prognostication. Asia Pac J Ophthalmol (Phila) 2017;6:186-96.

12. Hutchinson L. Immunotherapy: Cul-TIL-vating uveal melanoma regression. Nat Rev Clin Oncol 2017;14:328-9.

13. Glanville J, Kendrick T, McNally R, et al. Research output 
on primary care in Australia, Canada, Germany, the Netherlands, the United Kingdom, and the United States: bibliometric analysis. BMJ 2011;342:d1028.

14. Seriwala HM, Khan MS, Shuaib W, et al. Bibliometric analysis of the top 50 cited respiratory articles. Expert Rev Respir Med 2015;9:817-24.

15. Khan MS, Ullah W, Riaz IB, et al. Top 100 cited articles in cardiovascular magnetic resonance: a bibliometric analysis. J Cardiovasc Magn Reson 2016;18:87.

16. Hirsch JE. An index to quantify an individual's scientific research output. Proc Natl Acad Sci USA 2005;102:16569-72.

17. Kivelä TT. The first description of the complete natural history of uveal melanoma by two Scottish surgeons, Allan Burns and James Wardrop. Acta Ophthalmol 2018;96:203-14.

18. Kaliki S, Shields CL. Uveal melanoma: relatively rare but deadly cancer. Eye (Lond) 2017;31:241-57.

19. Park SJ, Oh C-M, Kim BW, et al. Nationwide Incidence of Ocular Melanoma in South Korea by Using the National Cancer Registry Database (1999-2011). Invest Ophthalmol Vis Sci 2015;56:4719-24.

20. Virgili G, Gatta G, Ciccolallo L, et al. Incidence of uveal melanoma in Europe. Ophthalmology 2007;114:2309-15.

21. Van Raamsdonk CD, Griewank KG, Crosby MB, et al. Mutations in GNA11 in uveal melanoma. N Engl J Med 2010;363:2191-9.

22. Harbour JW, Onken MD, Roberson EDO, et al. Frequent mutation of BAP1 in metastasizing uveal melanomas. Science 2010;330:1410-3.

23. Van Raamsdonk CD, Bezrookove V, Green G, et al. Frequent somatic mutations of GNAQ in uveal melanoma and blue naevi. Nature 2009;457:599-602.

24. Li Y, He J, Qiu C, et al. The oncolytic virus H101 combined with GNAQ siRNA-mediated knockdown reduces uveal melanoma cell viability. J Cell Biochem 2019;120:5766-76.

25. Li P, He J, Yang Z, et al. ZNNT1 long noncoding RNA induces autophagy to inhibit tumorigenesis of uveal melanoma by regulating key autophagy gene expression. Autophagy 2020;16:1186-99.

26. Feng X, Degese MS, Iglesias-Bartolome R, et al. Hippoindependent activation of YAP by the GNAQ uveal melanoma oncogene through a trio-regulated rho GTPase signaling circuitry. Cancer Cell 2014;25:831-45.

27. Yoo JH, Shi DS, Grossmann AH, et al. ARF6 Is an Actionable Node that Orchestrates Oncogenic GNAQ Signaling in Uveal Melanoma. Cancer Cell
2016;29:889-904.

28. Chen X, Wu Q, Depeille P, et al. RasGRP3 Mediates MAPK Pathway Activation in GNAQ Mutant Uveal Melanoma. Cancer Cell 2017;31:685-696.e6.

29. Feng X, Arang N, Rigiracciolo DC, et al. A Platform of Synthetic Lethal Gene Interaction Networks Reveals that the GNAQ Uveal Melanoma Oncogene Controls the Hippo Pathway through FAK. Cancer Cell 2019;35:457-472.e5.

30. Moore AR, Ceraudo E, Sher JJ, et al. Recurrent activating mutations of G-protein-coupled receptor CYSLTR2 in uveal melanoma. Nat Genet 2016;48:675-80.

31. Harbour JW, Roberson EDO, Anbunathan H, et al. Recurrent mutations at codon 625 of the splicing factor SF3B1 in uveal melanoma. Nat Genet 2013;45:133-5.

32. Martin M, Maßhöfer L, Temming P, et al. Exome sequencing identifies recurrent somatic mutations in EIF1AX and SF3B1 in uveal melanoma with disomy 3. Nat Genet 2013;45:933-6.

33. Yavuzyigitoglu S, Koopmans AE, Verdijk RM, et al. Uveal Melanomas with SF3B1 Mutations: A Distinct Subclass Associated with Late-Onset Metastases. Ophthalmology 2016;123:1118-28.

34. Gupta MP, Lane AM, DeAngelis MM, et al. Clinical Characteristics of Uveal Melanoma in Patients With Germline BAP1 Mutations. JAMA Ophthalmol 2015;133:881-7.

35. Pan H, Jia R, Zhang L, et al. BAP1 regulates cell cycle progression through $\mathrm{E} 2 \mathrm{~F} 1$ target genes and mediates transcriptional silencing via $\mathrm{H} 2 \mathrm{~A}$ monoubiquitination in uveal melanoma cells. Int J Biochem Cell Biol 2015;60:176-84.

36. Szalai E, Wells JR, Ward L, et al. Uveal Melanoma Nuclear BRCA1-Associated Protein-1 Immunoreactivity Is an Indicator of Metastasis. Ophthalmology 2018;125:203-9.

37. Landreville S, Agapova OA, Matatall KA, et al. Histone deacetylase inhibitors induce growth arrest and differentiation in uveal melanoma. Clin Cancer Res 2012;18:408-16.

38. Yan D, Zhou X, Chen X, et al. MicroRNA-34a inhibits uveal melanoma cell proliferation and migration through downregulation of c-Met. Invest Ophthalmol Vis Sci 2009;50:1559-65.

39. Chen X, Wang J, Shen H, et al. Epigenetics, microRNAs, and carcinogenesis: functional role of microRNA-137 in uveal melanoma. Invest Ophthalmol Vis Sci 2011;52:1193-9. 
40. Yan D, Dong XD, Chen X, et al. Role of microRNA-182 in posterior uveal melanoma: regulation of tumor development through MITF, BCL2 and cyclin D2. PLoS One 2012;7:e40967.

41. Zhang L, He X, Li F, et al. The miR-181 family promotes cell cycle by targeting CTDSPL, a phosphatase-like tumor suppressor in uveal melanoma. J Exp Clin Cancer Res 2018;37:15.

42. Liu J, Ma L, Li C, et al. Tumor-targeting TRAIL expression mediated by miRNA response elements suppressed growth of uveal melanoma cells. Mol Oncol 2013;7:1043-55.

43. Zhou Y, Song X, Jia R, et al. Radiation-inducible human tumor necrosis factor-related apoptosis-inducing ligand (TRAIL) gene therapy: a novel treatment for radioresistant uveal melanoma. Pigment Cell Melanoma Res 2010;23:661-74.

44. Naus NC, Zuidervaart W, Rayman N, et al. Mutation analysis of the PTEN gene in uveal melanoma cell lines. Int J Cancer 2000;87:151-3.

45. Rimoldi D, Salvi S, Liénard D, et al. Lack of BRAF mutations in uveal melanoma. Cancer Res 2003;63:5712-5.
46. Zuidervaart W, van Nieuwpoort F, Stark M, et al. Activation of the MAPK pathway is a common event in uveal melanomas although it rarely occurs through mutation of BRAF or RAS. Br J Cancer 2005;92:2032-8.

47. Algazi AP, Tsai KK, Shoushtari AN, et al. Clinical outcomes in metastatic uveal melanoma treated with PD-1 and PD-L1 antibodies. Cancer 2016;122:3344-53.

48. Rodrigues M, Mobuchon L, Houy A, et al. Outlier response to anti-PD1 in uveal melanoma reveals germline MBD4 mutations in hypermutated tumors. Nat Commun 2018;9:1866.

49. Forget M-A, Haymaker C, Hess KR, et al. Prospective Analysis of Adoptive TIL Therapy in Patients with Metastatic Melanoma: Response, Impact of Anti-CTLA4, and Biomarkers to Predict Clinical Outcome. Clin Cancer Res 2018;24:4416-28.

50. Chandran SS, Somerville RPT, Yang JC, et al. Treatment of metastatic uveal melanoma with adoptive transfer of tumour-infiltrating lymphocytes: a single-centre, two-stage, single-arm, phase 2 study. Lancet Oncol 2017;18:792-802.
Cite this article as: Xie M, Wu Q, Wang Y, Ge S, Fan X. Publication trends of research on uveal melanoma during 2000-2020: a 20-year bibliometric study. Ann Transl Med 2020;8(21):1463. doi: 10.21037/atm-20-3700 